\title{
Reliability Design of Mechanical Systems Such as Compressor Subjected to Repetitive Stresses ${ }^{\dagger}$
}

\author{
Seongwoo Woo ${ }^{1 *}$, Dennis L. O’Neal ${ }^{2}$, Samson Mekbib Atnaw ${ }^{1}$ and Muluneh Mekonnen Tulu ${ }^{1}$ \\ 1 Department of Mechanical Engineering, College of Electrical and Mechanical Engineering, Addis Ababa \\ Science \& Technology University, PO box 16417 Addis Ababa, Ethiopia; \\ muluneh.mekonnen@aastu.edu.et (M.M.T.) \\ 2 Department of Mechanical Engineering, Dean of Engineering and Computer Science, Baylor University, \\ Waco, TX 76798-7356, USA; dennis_oneal@baylor.edu \\ * Correspondence: twinwoo@yahoo.com; Tel.: +251-90-047-6711 \\ + Presented at the title, place, and date.
}

Citation: Woo, S.; O’Neal, D.L.; Atnaw, S.M.; Tulu, M.M. Reliability Design of Mechanical Systems Such as Compressor Subjected to Repetitive Stresses. 2021, 3, x. https://doi.org/10.3390/xxxxx

Published: 22 February 2021

Publisher's Note: MDPI stays neutral with regard to jurisdictional claims in published maps and institutional affiliations.

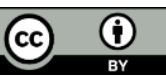

Copyright: (c) 2021 by the authors. Submitted for possible open access publication under the terms and conditions of the Creative Commons Attribution (CC BY) license (http://creativecommons.org/licenses/by/4.0/).

\begin{abstract}
This paper suggests parametric accelerated life testing (ALT) as a systematic reliability technique to generate the reliability quantitative (RQ) specification such as mission cycle for identifying design flaws in mechanical systems as exerting the accelerated load, defined as the reverse of stress ratio, R. Parametric ALT therefore is a procedure to improve the fatigue for mechanical products subjected to repetitive loading. It include: (1) a system BX lifetime shaped on the parametric ALT plan, (2) a fatigue failure and design, (3) tailored ALTs with alternatives, and (4) an assessment of whether the design(s) of the product attains the targeted BX lifetime. A BX life ideas, a life-stress model, and a sample size formulation for parametric ALT are proposed. A reciprocating compressor in a domestic refrigerator is utilized to explain this methodology. The compressor was subjected to repetitive impact loading due to pressure difference between condenser and evaporator, which resulting in the compressor field failure. To analyze and conduct parametric ALTs, as mass/energy balance was utilized on the vapor-compression refrigerating cycle, a simple pressure loading of the compressor in operating the refrigerator was investigated. At the first ALT, compressor locked due to the fractured suction reed valve made of Sandvik $20 \mathrm{C}$ carbon steel $(1 \% \mathrm{C}, 0.25 \% \mathrm{Si}, 0.45 \% \mathrm{Mn})$. The dominant failure modes of the suction reed valve in the parametric ALTs were established to be very close to that of the fractured product from the marketplace. The root cause of the fatigue failure of suction reed valve was an amount of overlap between the suction reed valve and the valve plate in combination of repeated pressure loading in the compressor. To supply sufficient mechanical strength, the design faults were altered by the trespan dimensions, tumbling process, a ball peening and brushing process for the valve plate. At the second ALT, compressor locked due to the intrusion between the crankshaft and thrust washer. The corrective action plan was to give heat treat the surface of crankshaft made of cast iron $(0.45 \% \mathrm{C}, 0.25 \% \mathrm{Si}, 0.8 \% \quad \mathrm{Mn}, 0.03 \% \mathrm{P})$. After these alternations, there were no issues at the third ALT. The lifetime of the compressor was ensured to have B1 life 10 years.
\end{abstract}

Keywords: fatigue failure; design flaws; mechanical system; parametric ALT; compressor

\section{Introduction}

Because of the customers' continual requirement in the global market, refrigerator is designed to have a low energy use and high reliability. For these (intended) functions, the compressor might be reshaped to improve its overall energy efficiency on an annual basis. Frequently, it necessitates newly designed attributes for the product that should be swiftly brought to the marketplace. Nevertheless, without enough testing or expectation of how the features may be utilized, their introduction may grow product failures from the marketplace and oppositely affect the company's brand image. These added attributes for the 
product should be included and evaluated completely in new design specifications before being launched into the marketplace. Thus, reliability quantitative (RQ) specifications using proper methodology should be introduced [1-2].

Newly designed rotary compressors in 1987 irregularly locked from the marketplace. Because oil metal sludge, separated from the sintering crankshaft and shaped in the refrigeration cycle, choked the capillary tubes, the refrigerator no longer functioned. There therefore were huge recalls of the compressor to stop a dominant failure mode such as a choking of the compressor from field [3]. A compressor intends to increases the refrigerant pressure in a refrigeration cycle by adapting proper mechanism such as crankshaft. Compressor is subjected to repeated stress due to internal pressure loadings during its lifetime. To prevent the compressor recall, any flawed arrangements should be discovered and modified by experimental methods such as parametric ALT that can create reliability quantitative $(R Q)$ specifications before the product releases.

Robust design methods such as the Taguchi approach [4,5] and statistical design of experiments (DOE)[6] were evolved to conduct the most favorable design for products. Mainly, Taguchi's methodology utilizes design parameter skill to place it in a proper position where "noise" parameters do not have a consequence on the output. Accordingly, the proper design parameters of mechanical systems can be chosen to look for them and their levels. However, this methodology does not identify the failure mechanism such as fatigue and pursuits the system optimization. In other words, if there is design fault when load is exerted, product will fail in its lifetime. Because lots parameters for an optimal design of mechanical structure should be considered, enormous computations are required. As there are still design faults in the structural system, it results in product recalls.

Due to material defects such as micro-voids and contacts when subjected to loads, fatigue is one of the main root causes of damage in metallic metallic members, which explains about $80 \%$ to $95 \%$ of all structural failures [7]. Fatigue failure in ductile metals shows itself in the form of cracks that propagate in high stress concentration such as grooves, holes, etc. These failures can influence the reliability of mechanical apparatus such as automobiles in motion, aircraft wings, ships at marine, jet engines, nuclear reactors, and land-based turbines. The fatigue mechanisms include three fluctuating stress/time modes: 1) symmetrical about zero stresses, 2) asymmetrical about zero stresses, and 3 ) random stress cycles. The fatigue life may depends on the stress ratio, $R\left(=\sigma_{\min } / \sigma_{\max }\right)$ [8]. That is, in periodic patterns the peaks on both the high side (maximum) and the low side (minimum) are critical. As exerting the elevated load, defined as the inverse of stress ratio, $R$, accelerated life testing (ALT) can be considered to find the design flaws.

The ALT was studied as an alternative method based on reliability block diagram [9]. It includes test planning for the system, failure mechanics such as fatigue, elevated procedures, sample size equation, etc. Elsayed [10] grouped statistical, physics/statistics, and physics/experimental-found prototypes for analysis. Meeker [11] presented many practical directions to arrange an ALT. Performing an ALT $[12,13]$ necessitate numerous notions such as the BX life for the product test plan, a life-stress model, sample size formulation, and fracture mechanics [14-16] because failure may happen abruptly from the weak parts in a system. Contemporary experimental methods [17-21] may fail to reproduce the design defects of component in a multi-module product because these methods assess inadequate part samples and do not recognize the failure(s) that really happen in the field.

To fulfil the structural design of a mechanical system, engineers have utilized the design methods such as fracture mechanics and strength of materials [22]. As quantum mechanics has been advanced, designers recognized that failures came from micro-void coalescence (MVC) and found some metallic alloys or numerous engineering plastics [23]. To discover the fatigue of a mechanical system, a life-stress model must be incorporated with the conventional design methods and relevant technique of recognizing the failure of electronic parts due to pre-existed defects or tiny cracks. It is not feasible to model it by Finite element methods (FEMs) [24]. 
This study suggests a parametric ALT as a reliability methodology that can produce the RQ specifications - mission cycles - for recognizing and correcting the design flaws of a mechanical systems. It includes: (1) A product BX lifetime formed on ALT plan, (2) a load analysis for ALT, (3) customized ALTs with the alternatives, and (4) an evaluation of whether the eventual design(s) of the system attains the real BX lifetime. A newly designed compressor in a domestic refrigerator subjected to repeated pressure loading is supplied as an example.

\section{Parametric ALT for Mechanical System}

\subsection{Definition of BX lifetime}

Within a mechanical system, transfers of power for obtaining mechanical advantages are used in tasks that involve forces and movement by adapting specific product mechanisms [25]. In the process, products are subjected to repeated stresses. For example, to keep nourishment natural, a refrigerator is intended to supply chilled air from the heat exchanger such as evaporator to the refrigerator (or freezer) compartments. It often is made up of dissimilar modules: the cabinet, door, internal fixtures (shelves and drawers), controls and instruments, electric motor, compressor, heat exchangers (evaporator and condenser), water supply device, and different various components. A refrigerator has roughly 2,000 parts. A refrigerator's lifetime is targeted to have no less than a B20 life 10 years. If a refrigerator consists of 20 modules and each module has 100 parts, the lifetime of each module should be aimed to have a B1 life 10 years. The desired product lifetime depends on the problematic module such as compressor, which has design faults (Figure 1).

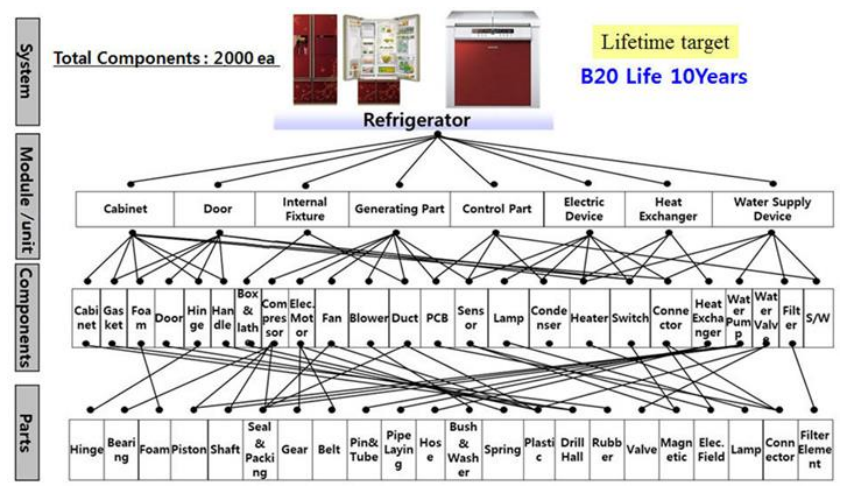

(a)

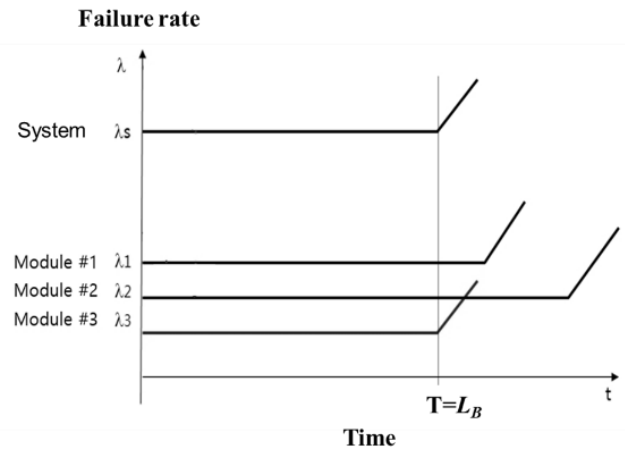

(b)

Figure 1. Product lifetime determined by newly designed module (a) Classification of multi-module refrigerator; (b) System lifetime $L в$ and failure rate $\lambda_{\mathrm{s}}$. 
To conduct ALT, BX life, $L B$, is necessitated as an index of product lifetime. It can be explained as the elapsed time period at which $X \%$ of a population of product shall be unsucessful. Therefore, 'BX life Y years' is a good expression for product lifetime that can correctly dictate the cumulative failure rate and follows the market requirements. For instance, if a product lifetime has B20 life 10 years, then $20 \%$ of population shall fail for 10 working years. On the other hand, the mean time to failure (MTTF) - B60 lifetime -is not suitable for the product lifetime, which is too long time to fail the $60 \%$ of the population in a product. We know that BX life shows a better suitable measure of lifetime.

\subsection{Setting A Whole Parametric ALT Plan}

For a stated period of time, the product reliability such as compressor can be explained as the system capability to intended task under specified environmental/operational states [25]. It might be provided with picture as "the bathtub curve" that composes three regions. First, in the initial product life there is some reducing failure rate. Secondly, in its middle life there is some stable failure rate. Lastly, there is a growing failure rate to the finale life. If a product follows its pattern, it might not succeed from the marketplace due to the high failure rates and short lifetime of the product due to the inherent design defects. Manufacturers need to enhance the product design by increasing its reliability targets to (1) eliminate untimely failures, (2) lessen random failures over the system lifetime, and (3) lengthen system lifetime. As the design of a mechanical system improves, its failure rate in the marketplace should decease and the product lifetime should be enlarged. For such circumstances, the conventional bathtub curve might be changed to an unswerving line in Figure 2.

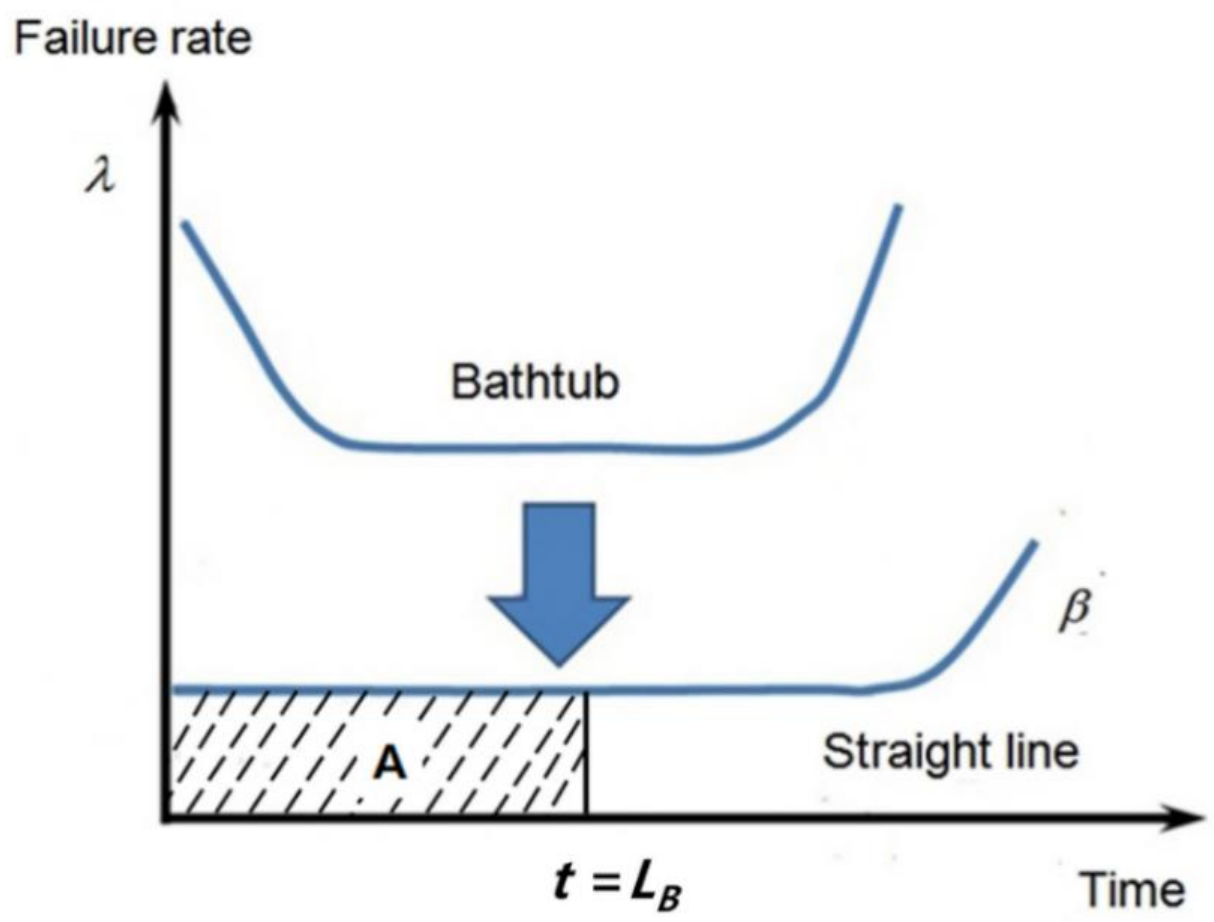

Figure 2. Bathtub curve and modified straight line. 
The failure rate on the bathtub (or straight line) can be defined as

$$
\lambda=\frac{f}{R}=\frac{d F / d t}{R}=\frac{(1-R)^{\prime}}{R}=\frac{-R^{\prime}}{R}
$$

where $\lambda$ is the failure rate, $f$ is the failure density function, $R$ is reliability, and $F$ is unreliability.

If Equation (1) is integrated over time, we can obtain the $X \%$ cumulative failure $F\left(L_{B}\right)$ at $B X$ life, $L B$. That is,

$$
\int \lambda d t=-\ln R
$$

That is to say, it can be expressed as:

$$
A=\langle\lambda\rangle \cdot L_{B}=\int_{0}^{L_{B}} \lambda(t) \cdot d t=-\ln R\left(L_{B}\right)=-\ln (1-F) \cong F\left(L_{B}\right)
$$

Because the straight line that follows an exponential distribution has a low failure rate, the reliability of mechanical product could be stated as product of the lifetime Lв and failure rate $\lambda$ :

$$
\mathrm{R}\left(\mathrm{L}_{\mathrm{B}}\right)=1-F\left(L_{B}\right)=\mathrm{e}^{-\lambda \mathrm{L}_{\mathrm{B}}} \cong 1-\lambda \mathrm{L}_{\mathrm{B}}
$$

This relation is appropriate below about $20 \%$ of cumulative failure [26]. After finding the problematic structures and modifying them by parametric ALT, the mechanical product can be attainable by targeting the lifetime Lв and failure rate $\lambda$ (Figure 3 ).

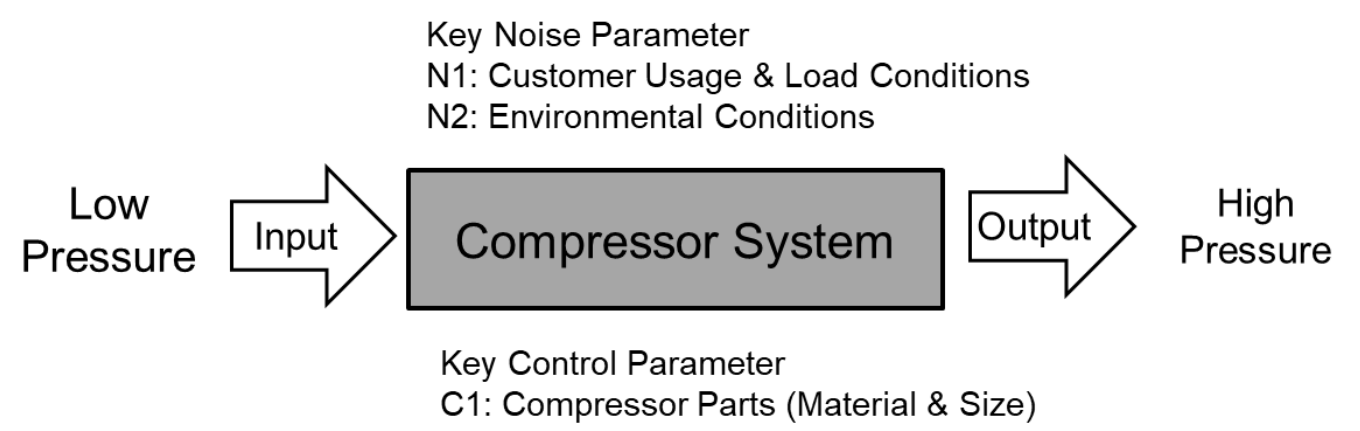

Figure 3. Parameter diagram of compressor system (example).

In seeking to enhance the lifetime target of a mechanical system through an ALT examination, there are three potential product modules: (1) An altered independent units, (2) a newly designed independent units, and (3) an alike independent units to the previous design base on demand in the marketplace. The newly designed compressor in the refrigerator examined here as an instance study was a modified module that had design faults that had to be rectified because customers want improved its energy efficiency.

The modified independent units D from the market data shown in Table 1 had a failure rate of $0.31 \%$ per year and a B1 life 3.2 years. The lifetime of compressor from the field data was expected to have a B1 life 1.6 years because it had a failure rate of $0.62 \%$ per year. To answer customer requests, a new lifetime for the mechanical system such as compressor was targeted to have B1 life 10 years with a cumulative failure rate of one percent. 
Table 1. Whole ALT plan of mechanical system such as modules in a refrigerator.

\begin{tabular}{|c|c|c|c|c|c|c|c|c|}
\hline \multirow{3}{*}{$\frac{\text { Modules }}{\text { A }}$} & \multicolumn{2}{|c|}{ Market Data } & \multicolumn{4}{|c|}{ Anticipated Reliability } & \multicolumn{2}{|c|}{ Objective Reliability } \\
\hline & \multirow{2}{*}{$\begin{array}{c}\text { Failure Rate Per } \\
\text { Year, \%/year } \\
0.35\end{array}$} & \multirow{2}{*}{$\begin{array}{c}\begin{array}{c}\text { BX Life, } \\
\text { Year }\end{array} \\
2.9\end{array}$} & \multicolumn{3}{|c|}{$\begin{array}{c}\text { Failure Rate Per } \\
\text { Year, \%/Year }\end{array}$} & \multirow{2}{*}{$\begin{array}{c}\begin{array}{c}\text { BX Life, } \\
\text { Year }\end{array} \\
2.9\end{array}$} & \multirow{2}{*}{$\begin{array}{c}\begin{array}{c}\text { Failure Rate Per } \\
\text { Year, \%/Year }\end{array} \\
0.10\end{array}$} & \multirow{2}{*}{$\begin{array}{c}\begin{array}{c}\text { BX Life, } \\
\text { Year }\end{array} \\
10(B X=1.0)\end{array}$} \\
\hline & & & Similar & $\times 1$ & 0.35 & & & \\
\hline $\mathrm{B}$ & 0.24 & 4.2 & New & $\times 5$ & 1.20 & 0.83 & 0.10 & $10(\mathrm{BX}=1.0)$ \\
\hline $\mathrm{C}$ & 0.30 & 3.3 & Similar & $\times 1$ & 0.30 & 3.33 & 0.10 & $10(\mathrm{BX}=1.0)$ \\
\hline $\mathrm{D}$ & 0.31 & 3.2 & Modified & $\times 2$ & 0.62 & 1.61 & 0.10 & $10(\mathrm{BX}=1.0)$ \\
\hline E & 0.15 & 6.7 & Modified & $\times 2$ & 0.30 & 3.33 & 0.10 & $10(\mathrm{BX}=1.0)$ \\
\hline Others & 0.50 & 10.0 & Similar & $\times 1$ & 0.50 & 10.0 & 0.50 & $10(\mathrm{BX}=5.0)$ \\
\hline Product & 1.9 & 2.9 & - & - & 3.27 & 0.83 & 1.00 & $10(\mathrm{BX}=10)$ \\
\hline
\end{tabular}

\subsection{Failure Mechanics and Parametric ALT for Design}

As stated in section 2.1, mechanical systems typically move energy and power from one location to another through mechanical mechanisms. For instance, a compressor as one of mechanical system elevates the refrigerant pressure by crank-shaft mechanism in a refrigeration system. Domestic compressor shall be subjected to repeated stress because of pressure loading in the process. If there is a design fault in the structure that causes an inadequate strength (or stiffness) when the loads are exerted, the mechanical system may suddenly fail before its anticipated lifetime. Fatigue due to design flaws can be distinguished by two elements: (1) the stress due to loads on the structural system and (2) the kind of materials (or form) utilized in the product. As identifying the system failure by a parametric ALT, a designer could optimally design components with proper shapes and materials. The product could sustain repetitive loads over its lifetime so that it could achieve the targeted reliability (Figure 4 ).

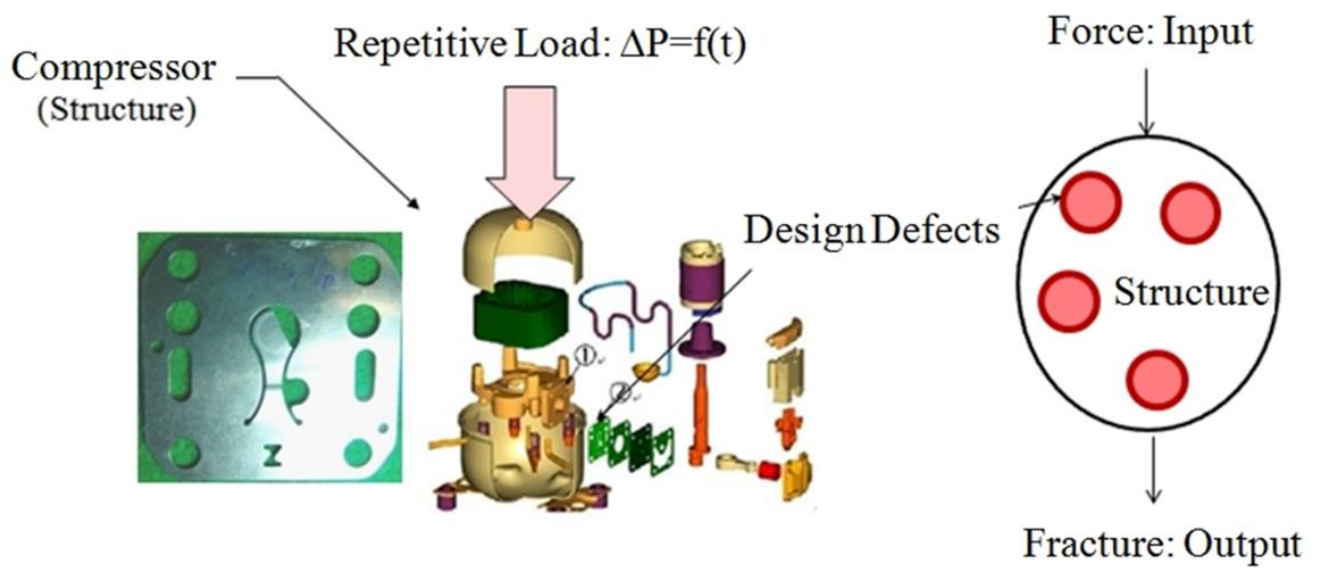

Figure 4. Fatigue on the system made by repeated loading and design defects.

The most important issue for a reliability test is how rapid the possible failure mode can reveal. To do this, it is obligatory to effectively express a failure model and decide the connected coefficients. First of all, we can create the life-stress (LS) model, which incorporates stresses and reaction parameters. This equation can explain various mechanical failures such as fatigue in the structure. Fatigue failure is on the rise, not due to design stresses in a complete component, but rather due to the appearance of a preexisting defect or small crack on the surface of a part.

Because mechanical failure such as fatigue starts from material defects formed on a micro or macroscopic scale level, we might define the life-stress model from such standpoint. 
For example, we can find out the following processes utilized for solid-state diffusion of impurities in silicon that is popularly used as semi-conduct material as following process: electro-migration-induced voiding, growth of chloride ions, and catching of electrons or holes. When electric magneto-motive force, $\xi$, is applied, we know that the impurities such as void in material, which were formed by electronic movement, is easily migrated because the barrier of junction energy is lowered and distorted/phase-shifted. The junction equation $\mathrm{J}$ for solid-state diffusion of impurities in silicon might be stated as follows [27,28] (Figure 5):

$$
J=[a C(x-a)] \cdot \exp \left[-\frac{q}{k T}\left(w-\frac{1}{2} a \xi\right)\right] \cdot v
$$

[Density/Area]·[Jump Probability]·[Jump Frequency]

$$
\begin{aligned}
& =-\left[a^{2} v e^{-q w / k T}\right] \cdot \cosh \frac{q a \xi}{2 k T} \frac{\partial C}{\partial x}+\left[2 a v e^{-q w / k T}\right] C \sinh \frac{q a \xi}{2 k T} \\
& =\Phi(x, t, T) \sinh (a \xi) \exp \left(-\frac{Q}{k T}\right) \\
& =B \sinh (a \xi) \exp \left(-\frac{Q}{k T}\right)
\end{aligned}
$$

where B is constant, $a$ is the interval between atoms, $\xi$ is the exerted field, $k$ is Boltzmann's constant, $T$ is temperature, and $Q$ is energy.

Electric magneto-motive force, $\xi$, is

\section{Applied}

\section{Initial state}

Potential, J

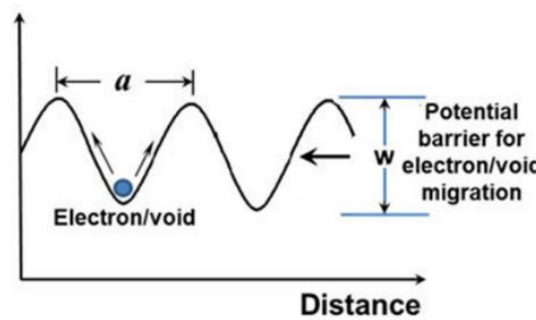

Potential, J

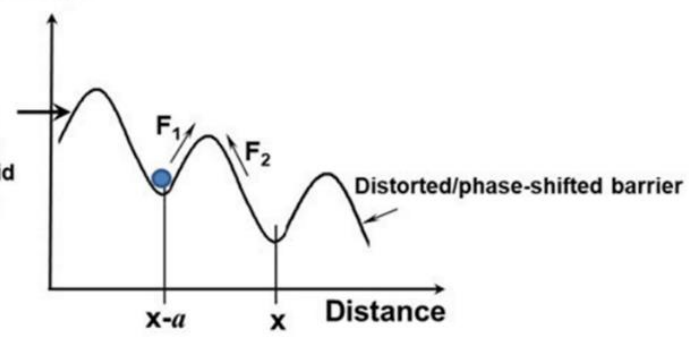

Figure 5. Potential change in material such as silicon after electrical field (or stress) is applied.

Contrastingly, the reaction process that relies on speed could be defined as

$$
K=K^{+}-K^{-}=a \frac{k T}{h} e^{-\frac{\Delta E-a S}{k T}}-a \frac{k T}{h} e^{-\frac{\Delta E+a S}{k T}}
$$




$$
=a \frac{k T}{h} e^{-\frac{\Delta E}{k T}} \sinh \left(\frac{a S}{k T}\right)=B \sinh (a S) \exp \left(-\frac{\Delta E}{k T}\right)
$$

where $\mathrm{K}$ is reaction rate, $\mathrm{S}$ is (chemical) effect, $\mathrm{T}$ is temperature, $\mathrm{k}$ is Boltzmann's constant, $E_{a}$ is the (activation) energy, and $\Delta$ is difference

The reaction rate $\mathrm{K}$ from Equations (5) and (6) could be abridged as

$$
K=B \sinh (a S) \exp \left(-\frac{E_{a}}{k T}\right)
$$

If Equation (7) takes a reverse function, the life-stress (LS) model might be defined as

$$
T F=A[\sinh (a S)]^{-1} \exp \left(\frac{E_{a}}{k T}\right)
$$

The sine hyperbolic expression $[\sinh (\mathrm{aS})]^{-1}$ in Equation (5) can be expressed as:

1. $(\mathrm{S})^{-1}$ in Equation (8) has a little linear effect at first,

2. $(S)^{-n}$ in Equation (8) has what is regarded as a medium effect, and

3. $\left(\mathrm{e}^{\mathrm{aS}}\right)^{-1}$ in Equation (8) is big in the end.

An ALT is normally performed in the medium range, and Equation (5) might be defined as

$$
T F=A(S)^{-n} \exp \left(\frac{E_{a}}{k T}\right)
$$

As the stress of a mechanical system may not be easy to measure during testing, Equation (9) must be redefined. When the power is defined as the multiplication of flows and effort, stresses may come from effort in a multi-port system (Table 2) [29].

Table 2. Power definition in a multi-port system.

\begin{tabular}{ccc}
\hline System & Effort, $\boldsymbol{e}(t)$ & Flow, $f(t)$ \\
\hline Translation system & Force, $F(t)$ & Velocity, $V(t)$ \\
Rotation system & Torque, $\tau(t)$ & Angular velocity, $\omega(t)$ \\
Pump, Compressor & Pressure difference, $\Delta P(t)$ & Volume flow rate, $Q(t)$ \\
Electric system & Voltage, $V(t)$ & Current, $i(t)$ \\
Magnetic & Magneto-motive force, $e_{m}$ & Magnetic flux, $\varphi$ \\
\hline
\end{tabular}

Stress is a physical amount that indicates the internal forces that adjacent particles of a continual material apply on each other. For a mechanical system, because stress comes from effort, Equation (9) might be restated as

$$
T F=A(S)^{-n} \exp \left(\frac{E_{a}}{k T}\right)=B(e)^{-\lambda} \exp \left(\frac{E_{a}}{k T}\right)
$$


where $\mathrm{A}$ and $\mathrm{B}$ are constants

To derive the acceleration factor (AF) that can mainly influence the assessment of fatigue strength in product, defined as the reverse of the stress ratio, $R\left(=\sigma_{\mathrm{min}} / \sigma_{\max }\right)$, from Equation (10), AF might be expressed as the proportion between the adequate elevated stress amounts and normal working conditions. AF might be altered to incorporate the effort ideas:

$$
A F=\left(\frac{S_{1}}{S_{0}}\right)^{n}\left[\frac{E_{a}}{k}\left(\frac{1}{T_{0}}-\frac{1}{T_{1}}\right)\right]=\left(\frac{e_{1}}{e_{0}}\right)^{\lambda}\left[\frac{E_{a}}{k}\left(\frac{1}{T_{0}}-\frac{1}{T_{1}}\right)\right]
$$

\subsection{Parametric ALT for Mechanical Systems}

To get the operation cycle of parametric ALTs from the objective BX lifetime on the experiment scheme in Table 1, the sample size formulation integrated with the AF should be obtained [1]. Currently, numerous methodologies have been suggested to decide sample size. The Weibayes model for Weibull analysis is a popularly recognized method of examining reliability data. However, it is hard to directly use because of the mathematical complication. The whole cases as failures $(r \geq 1)$ and no failures $(r=0)$ need to be separated. Consequently, it is possible to acquire a comprehensible sample size equation that might provide the mission cycle after proper assumptions.

In choosing the model parameters to maximize the likelihood function, the maximum likelihood estimation (MLE) statistic is a widespread way of approximating the parameters of a model. The characteristic life $\eta_{M L E}$ would be expressed as:

$$
\eta_{M L E}^{\beta}=\sum_{i=1}^{n} \frac{t_{i}^{\beta}}{r}
$$

where $\eta_{M L E}$ is the maximum likelihood estimate for the characteristic life, $n$ is the whole number of samples, $t_{i}$ is the exoeriment time for each sample, and $r$ is the failure numbers.

If the number of failures is $r \geq 1$ and the confidence level is $100(1-\alpha)$, the characteristic life, $\eta_{\alpha}$, can be approximated from Equation (9),

$$
\eta_{\alpha}^{\beta}=\frac{2 r}{\chi_{\alpha}^{2}(2 r+2)} \times \eta_{M L E}^{\beta}=\frac{2}{\chi_{\alpha}^{2}(2 r+2)} \times \sum_{i=1}^{n} t_{i}^{\beta} \text { for } r \geq 1
$$

where $\chi_{\alpha}^{2}()$ is the chi-square distribution when the $p$-value is $\alpha$.

Assuming there are no number of failures, $\ln (1 / \alpha)$ is identical to the chi-square value, $\frac{\chi_{\alpha}^{2}(2)}{2}[30]$. In other words,

$$
\left.p \text {-value }: \alpha=\int_{\chi_{\alpha}^{2}(2)}^{\infty}\left(\frac{e^{-\frac{x}{2}} x^{\frac{v}{2}-1}}{2^{\frac{v}{2}} \Gamma\left(\frac{v}{2}\right)}\right) d x=\int_{2 \ln \alpha^{-1}}^{\infty} \frac{e^{-\frac{x}{2}} x^{\frac{v}{2}-1}}{2^{\frac{v}{2}} \Gamma\left(\frac{v}{2}\right)}\right) d x \text { for } x \geq 0
$$

where $\Gamma$ is the gamma function and $v$ is the shape parameter

For $r=0$, the characteristic life $\eta_{\alpha}$ from Equation (13) might be defined as:

$$
\eta_{\alpha}^{\beta}=\frac{2}{\chi_{\alpha}^{2}(2)} \times \sum_{i=1}^{n} t_{i}^{\beta}=\frac{1}{\ln \frac{1}{\alpha}} \times \sum_{i=1}^{n} t_{i}^{\beta}
$$


As Equation (13) is proved for all occasions $r \geq 0$, characteristic life, $\eta_{\alpha}$, might be expressed as:

$$
\eta_{\alpha}^{\beta}=\frac{2}{\chi_{\alpha}^{2}(2 r+2)} \times \sum_{i=1}^{n} t_{i}^{\beta} \quad \text { for } r \geq 0
$$

If the logarithm in the Weilbull distribution is taken, the connection between characteristic life and BX life, $L_{B}$, might be defined as:

$$
L_{B}^{\beta}=\left(\ln \frac{1}{1-x}\right) \times \eta^{\beta}
$$

If the approximated characteristic life of the $p$-value $\alpha, \eta_{\alpha}$, in Equation (16), is changed into Equation (17), we acquire the BX life formulation:

$$
L_{B}^{\beta}=\left(\ln \frac{1}{1-x}\right) \times \frac{2}{\chi_{\alpha}^{2}(2 r+2)} \times \sum_{i=1}^{n} t_{i}^{\beta}
$$

As nearly all life testing commonly has inadequate samples to approximate the lifetime for the assigned failure numbers that might be less than that of the sample size, the plan experiment time can begin as:

$$
n h^{\beta} \geq \sum t_{i}^{\beta} \geq(n-r) \times h^{\beta}
$$

If Equation (19) is exchanged with Equation (18), the BX life equation might be redefined as:

$L_{B}^{\beta} \cong\left(\ln \frac{1}{1-x}\right) \times \frac{2}{\chi_{\alpha}^{2}(2 r+2)} \cdot n h^{\beta} \geq\left(\ln \frac{1}{1-x}\right) \times \frac{2}{\chi_{\alpha}^{2}(2 r+2)} \times(n-r) h^{\beta} \geq L_{B}^{* \beta}$

If Equation (20) is rearranged, the sample size formulation with the failure numbers can be defined as: the sample size Equation (21) can be simply close to:

$$
n \geq \frac{\chi_{\alpha}^{2}(2 r+2)}{2} \times \frac{1}{\left(\ln \frac{1}{1-x}\right)} \times\left(\frac{L_{B}^{*}}{h}\right)^{\beta}+r
$$

Because $\frac{\chi_{\alpha}^{2}(2 r+2)}{2} \cong(r+1)$ for $\alpha=0.6$ and $\ln (1-x)^{-1}=x+\frac{x^{2}}{2}+\frac{x^{3}}{3}+\cdots \cong x$,

$$
n \geq(r+1) \times \frac{1}{x} \times\left(\frac{L_{B}^{*}}{h}\right)^{\beta}+r
$$

where the sample size formulation can be restated as $n \sim$ (failure numbers +1$) \cdot(1 /$ cumulative failure rate) $\cdot((\text { target lifetime/(plan testing time }))^{\wedge} \beta+r$.

If Equation (11) is attached to the plan testing time $h$, Equation (22) might be replaced as:

$$
n \geq(r+1) \times \frac{1}{x} \times\left(\frac{L_{B}^{*}}{A F \cdot h_{a}}\right)^{\beta}+r
$$

If the lifetime target of a mechanical system such as the compressor in a domestic refrigerator is assigned to be $\mathrm{B} 1$ life 10 years, the operation cycles might be attained for an 
assigned set of samples subjected to the (impact) loading. In parametric ALTs, the design flaws of the new product might be recognized to fulfill the lifetime target.

\subsection{Case Study-Reliability Design of a Newly Designed Compressor in Domestic Refrigerator}

Unknown specified customer usage conditions and patterns, the suction reed valves in a compressors utilized from the marketplace were failing, causing to the compressor failure. Because the function of refrigerator including the compressor was lost, consumers would request to have the product changed. To answer the issue, it was critical to identify the failure mode of the compressor in the room or building equipped for scientific experiments. Apparently, the problematic compressor returned from the marketplace would have had apparent design defects: (1) Suction reed valve had an amount of overlap with the valve plate; and (2) The valve plate had a sharp-edged. As the suction reed valve impacts the valve plate, it will fail in its lifetime (Figure 6).
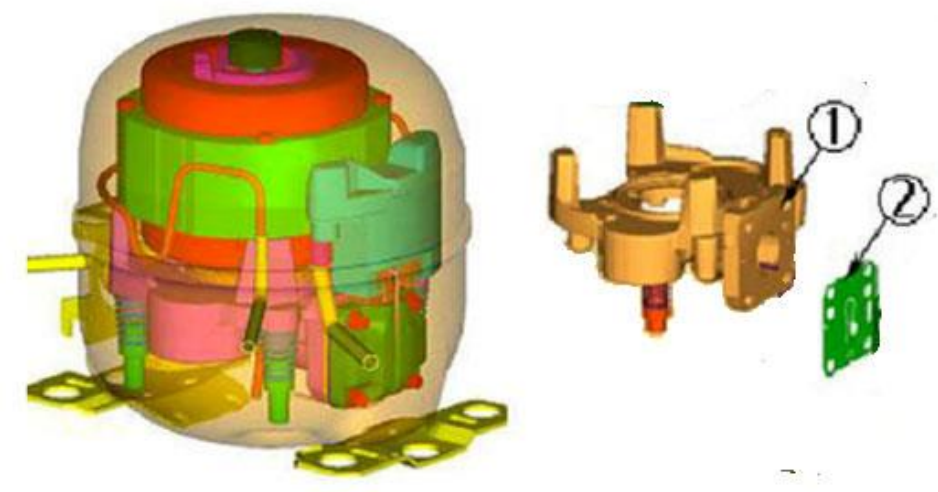

(a)
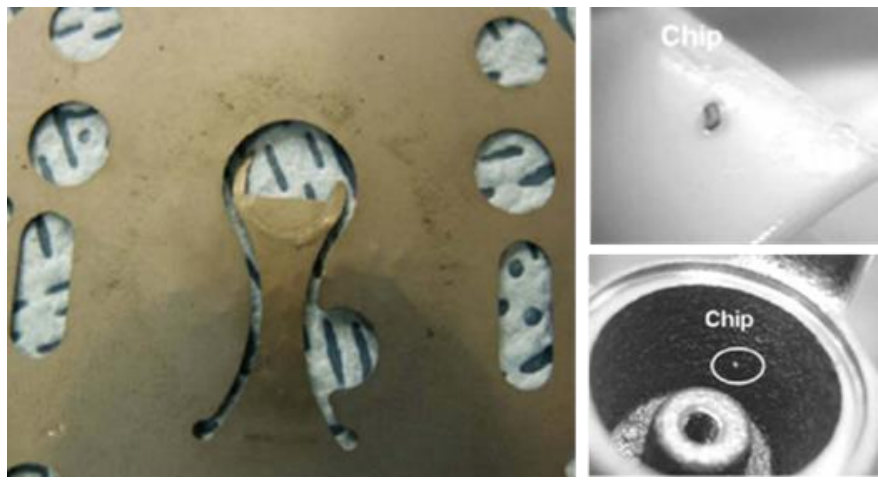

(b)

Figure 6. Fractured suction reed valve: (a) Valve plate and suction reed valve in compressor (b) Failed suction reed valve form the field

To stock the nourishment natural, the refrigerator is to supply chilled air from the heat exchanger such as evaporator to the freezer (or refrigerator) sections. It includes compressor, a condenser, a capillary tube and an evaporator. The refrigerator in a vaporcompression cycle acquire work from the compressor and moves heat from the heat 
exchanger such as evaporator to the condenser. A capillary tube manages refrigerant flow and releases the elevated pressure in the condenser to the low pressure in the evaporator. A compressor expands the pressure of the refrigerant (Figure 7).

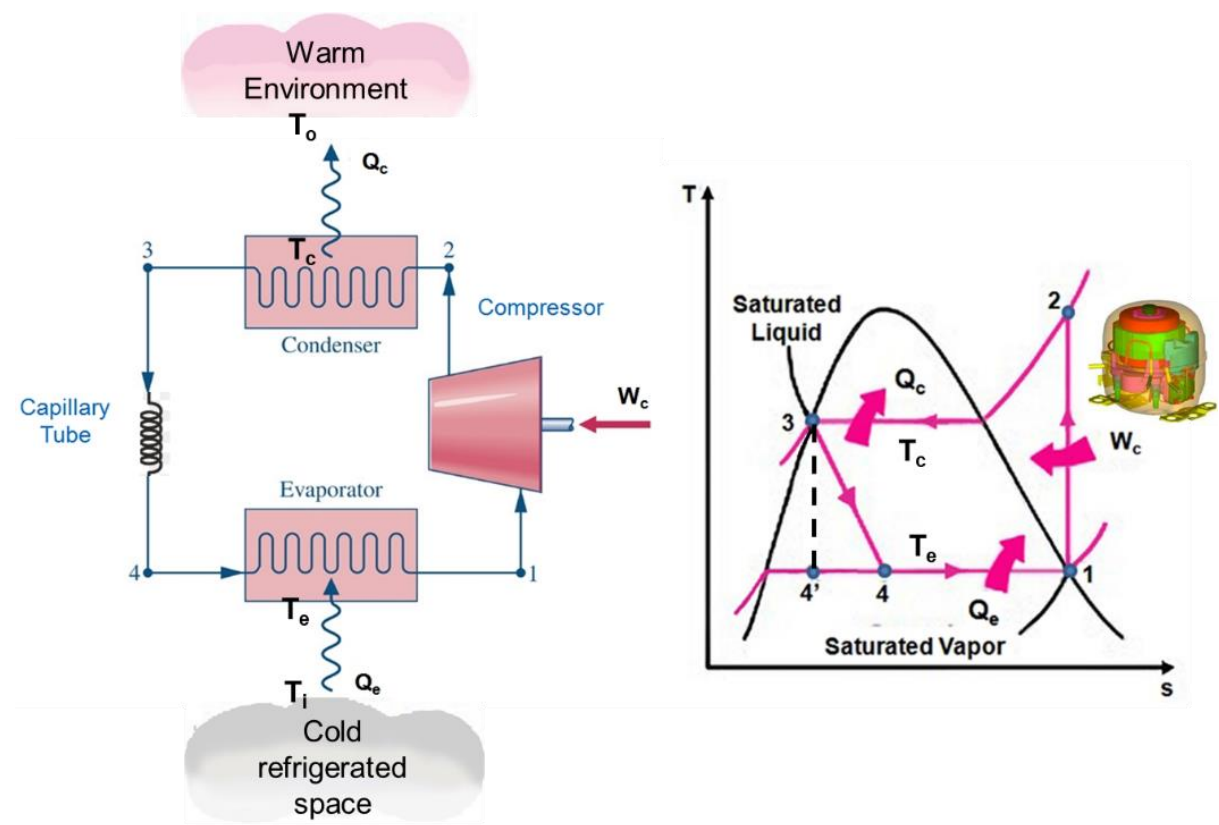

(a)

(b)

Figure 7. Compressor in the vapor-compression refrigeration cycle: (a) refrigerator cycle, (b) T-s diagram.

Compressors in a refrigerator thus are subjected to repeated stress due to pressure loads. If there is a design fault in the structural system that causes an inadequacy of strength when the loads are exerted, compressor may suddenly be unsuccessfu in its anticipated lifetime. After recognizing the system failure by parametric ALT, engineer can attain the the design of compressor shape in the best or most favourable way and choose a material type so the compressor can support repeated loads and its lifetime can be increased.

In a typical refrigeration cycle, it is required to decide both the condensing pressure, $P_{c}$, and evaporating pressure, $P_{e}$. when load examination is performed. These pressures rely on surrounding states, consumer usage states, and heat exchanger size in the preliminary design phase.

The internal stress of the compressor relies on the pressure difference between suction pressure, $\mathrm{P}_{\text {suc, }}$ and discharge pressure, $\mathrm{P}_{\text {dis. }}$ In other words,

$$
\Delta \mathrm{P}=P_{d i s}-P_{s u c} \cong P_{c}-P_{e}
$$

By reiterating the duty cycles, the mechanical system such as compressor experiences the controlling repeated stress. Under elevated states, the life-stress model (LS model) in Equation (10) can be restated as: 


$$
T F=A(S)^{-n} \exp \left(\frac{E_{a}}{k T}\right)=A(\Delta P)^{-\lambda} \exp \left(\frac{E_{a}}{k T}\right)
$$

where $A$ is constant, $k$ is Boltzman's constant, $E_{a}$ is the activation energy, $T$ is the absolute temperature, $n$ is the quotient and $\lambda$ is cumulative damage exponent in Palmgren-Miner's rule.

So the acceleration factor (AF) might be defined as:

$$
A F=\left(\frac{S_{1}}{S_{0}}\right)^{n}\left[\frac{E_{a}}{k}\left(\frac{1}{T_{0}}-\frac{1}{T_{1}}\right)\right]=\left(\frac{\Delta P_{1}}{\Delta P_{0}}\right)^{\lambda}\left[\frac{E_{a}}{k}\left(\frac{1}{T_{0}}-\frac{1}{T_{1}}\right)\right]
$$

where $\mathrm{S}_{1}\left(\right.$ or $\mathrm{P}_{1}$ ) is mechanical stress (or pressure difference) under elevated states, and $\mathrm{S}_{0}$ (or $\mathrm{P}_{0}$ ) is mechanical stress (or pressure difference) under typical states.

For a compressor system in a domestic refrigerator, the representative operating states were for a consumer span from 0 to $43^{\circ} \mathrm{C}$ with a humidity varying from $0 \%$ to $95 \%$. Design circumstances for functioning presumed the compressor system was subjected to 0.2 to $0.24 \mathrm{~g}$ of acceleration.

As the compressor works, the suction reed valve will operate to permit refrigerant to stream into it. A compressor is anticipated to cycle on and off 22 cycles per day. A worse case senario was also replicated with on and off 98 cycles per day. Under the worst cases, the compressor functioning for 10 years may occurs roughly 357,700 usage cycles.

For the worst case, pressure difference was 1.27 MPa and the compressor dome temperature was $90^{\circ} \mathrm{C}$. For parametric ALT, the pressure difference was increased to be $2.94 \mathrm{MPa}$ and the compressor dome temperature also was increased to be $120^{\circ} \mathrm{C}$. With accumulative damage factor, $\lambda$, of 2, whole AF calculated from Equation (26) was 7.3 (Table 3).

Table 3. Compressor ALT conditions.

\begin{tabular}{ccccc}
\hline \multicolumn{2}{c}{ System states } & Worst Case & ALT & AF \\
\hline Pressure $(\mathrm{MPa})$ & High-side & 1.27 & 2.94 & 5.36 (1) \\
& Low-side & 0.0 & 0.0 & \\
& $\Delta \mathrm{P}$ & 1.27 & 2.94 & $1.37(2)$ \\
Temperature $\left({ }^{\circ} \mathrm{C}\right)$ & Dome & 90 & 120 & 7.32 \\
Total AF & & & & \\
$(=(1) \times(2))$ & & & & \\
\hline
\end{tabular}

The test cycles of ALT computed from Equation (23) were 49,000 cycles for 100 sample units if the shape parameter, $\beta$, was assumed to have 2.0. The parametric ALT was designed to assure a lifetime target - B1 life 10 years - with approximately a $60 \%$ level of confidence that it would fail less than once during 49,000 cycles. We also applied the duty cycles of pressure difference between suction pressure, $\mathrm{P}_{\text {suc, }}$ and discharge pressure, $\mathrm{P}_{\text {dis. }}$

To evaluate the design of compressor, a simple vapor-compression refrigeration cycle was constructed. It included a compressor, condenser, capillary tube, and 
evaporator. Two 60-W lamps and a fan continued the temperature in the enveloped fiberglass package. A thermal switch affixed on the cover of compressor managed a 51 $\mathrm{m}^{3} / \mathrm{h}$ axial fan. The experiment states and their limits were established on the control board. As the test started, the high-side and low-side pressures were noticed on the pressure gauge or arrangement screen (Figure 8).
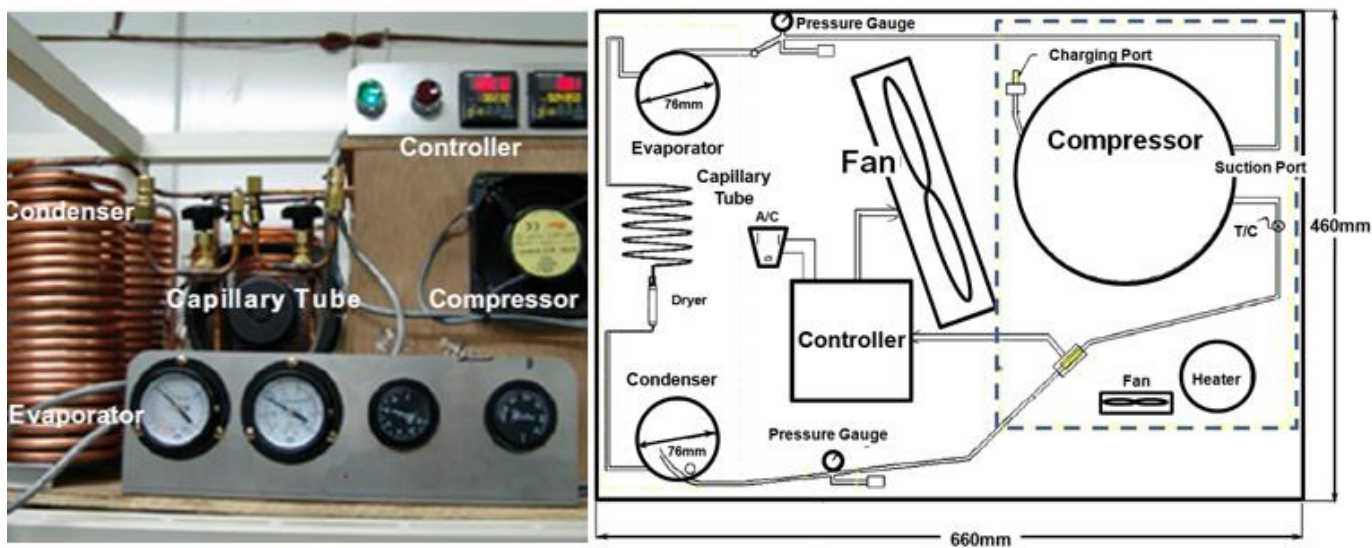

Figure 8. Apparatus for the parametic ALTs.

\section{Results and Discussion}

A sample in the first ALT $(\mathrm{n}=100)$ locked at 10,500 cycles. The affirmed shape parameter, $\beta$, formed from the market data, was 1.9. The forms and positions of the failure in the samples from the first ALT and the field were alike (Figure 9). The fracture originated from design faults of the suction reed valve: (1) had an amount of overlap with the valve plate, (2) had a sharp-edged on the valve plate, and (3) used a fragile material (Figure 6 \& 9).

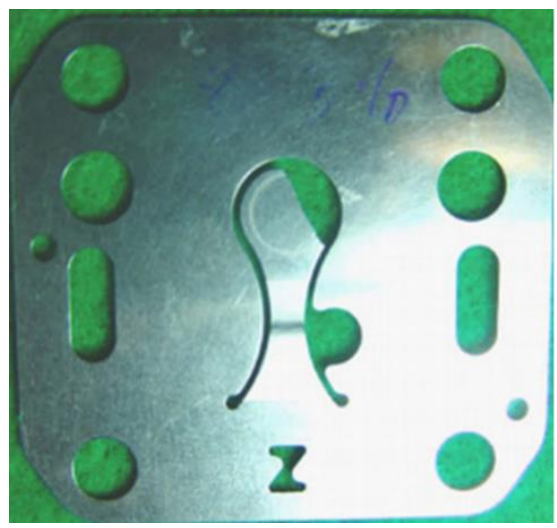

(a)

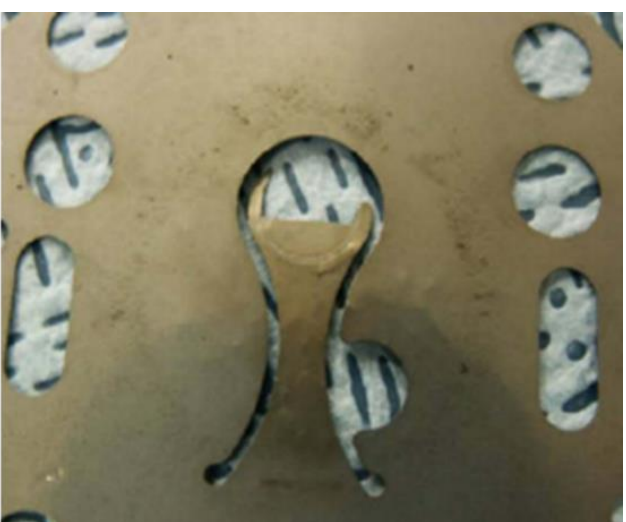

(b)

Figure 9. Fractured suction reed valve products from the markeplace and first ALT: (a) Fractured products from the markeplace, (b) Result after first parametric ALT

As the suction reed valve repeatedly hit the valve plate, it abruptly failed in its lifetime. The primary failure mode of the compressor was locking due to the fractured the suction reed valve. We knew that this systematic ALT method was well-founded for 
identifying the fatigue failure obtained from the marketplace. First, the form of the fractured suction reed valves from the marketplace and those in first ALT were very close. And we also knew that the ALT consequences and market failure data showed to have a same pattern on a Weibull plot (Figure 10).

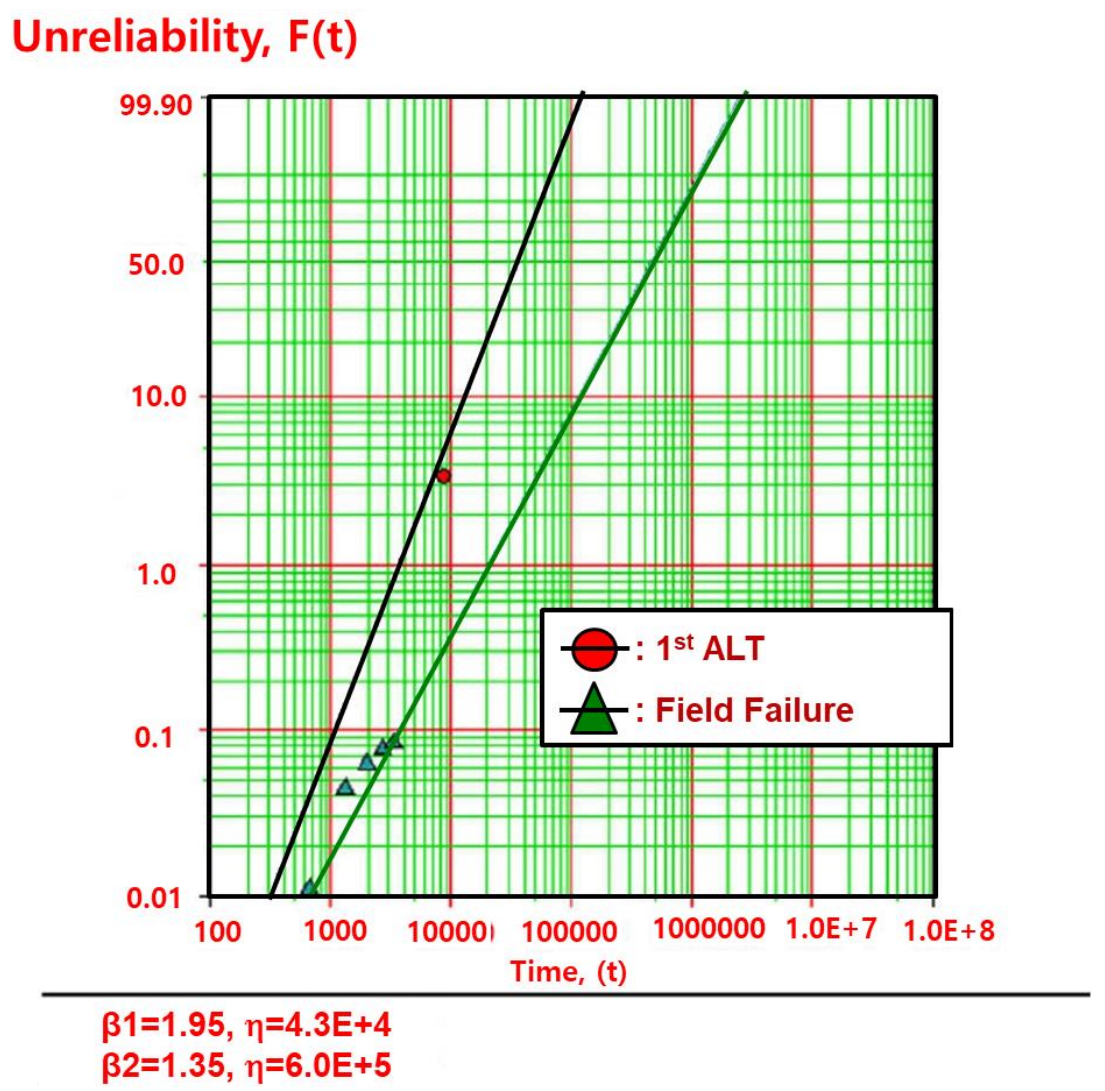

Figure 10. Market statistcs and consequences of ALT on Weibull chart.

Refrigerators returned from the marketplace had a main failure mode with no cooling because the compressor didn't work. Market data designated that the problematic compressors may have had design defects. Due to these faults, the repeated pressure loads could generate unexpected stresses on the suction reed valve, leading it to crack and propagate it to the end. To identify the dominent failure mode of the compressor, parametric ALTs were performed. Based on the first ALT and field data, we knew that the $\mathrm{AF}$ and $\beta$ values were 7.3 and 1.95 (Figure 10). For given test samples, the test cycles were calculated in Equation (23) if product lifetime was ensured to have B1 life 10 years.

In the first ALT, a compressor failed at 10,500 cycles. Breakdown of the troublesome compressors from the markeplace and the first ALT designated that the suction reed valves fractured in some areas where they overlapped with the valve plate. The unsuccessful appearance of the first ALT was very close to the ones from the markeplace. The experiment results affirmed that the compressor system was not properly designed to operate the suction reed valve. 
The root causes of the failed suction reed valve originated from the inappropriate design defects: (1) an amount of overlap with the valve plate; (2) a sharp-edged on the valve plate; and (3) fragile material (0.178t) utilized in the design of suction reed valve. These defects might lead the compressor system to fail abruptly as subjected to repeated pressure loads (Figure 11).

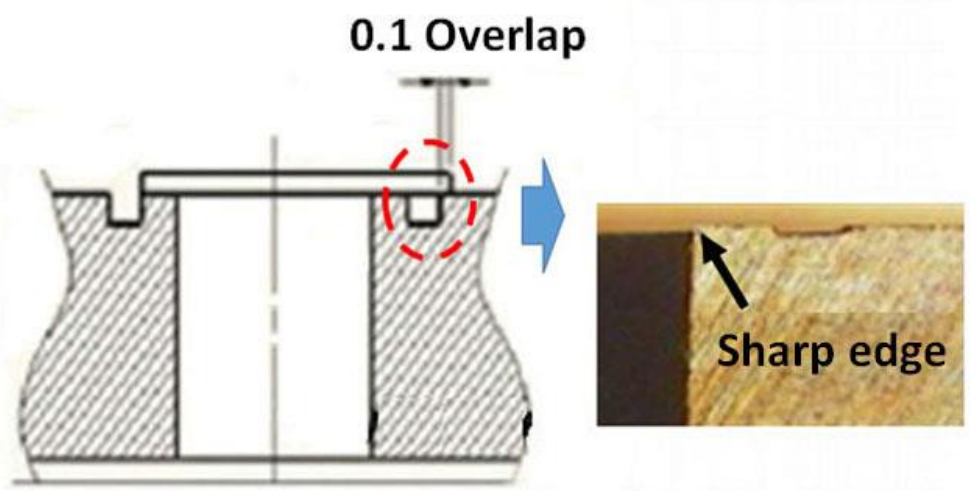

(a)

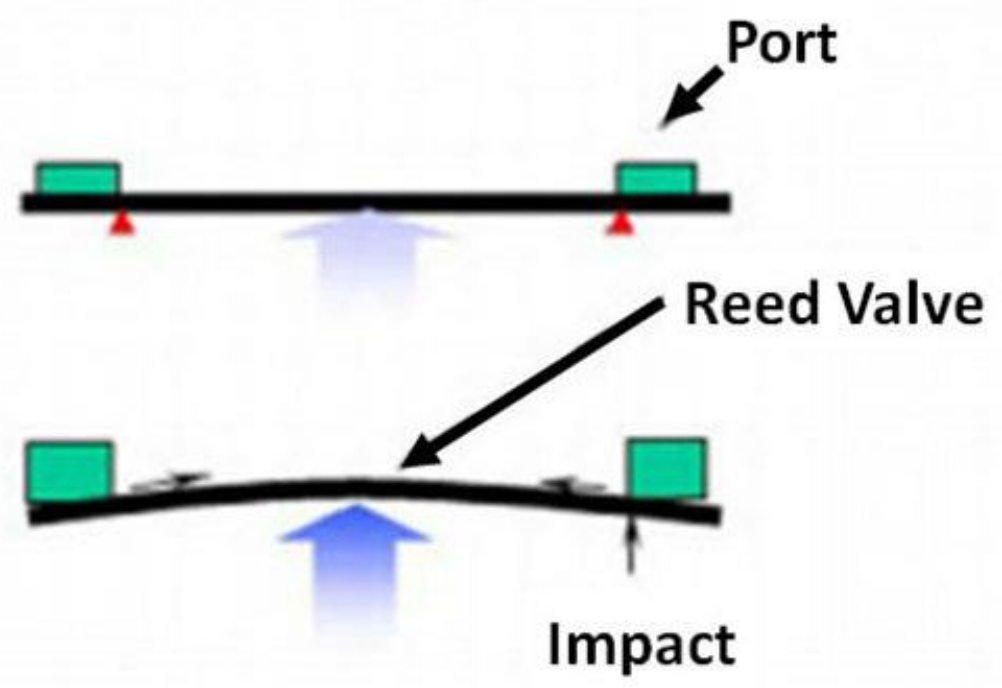

(b)

Figure 11. Structural flaws of suction reed and valve plate in a compressor: (a) Overlapped suction reed valve and valve plate with sharp edge (b) Impact load in combination of design flaws when compressor is operated

To stop the fractured suction reed valve from the repeated pressure stresses within the compressor's lifetime, the valve plate was corrected as follows: (1) Trespan size, C1 from $0.73 \mathrm{~mm}$ to $1.25 \mathrm{~mm}$; (2) Attaching ball peening and brush process, C2; (3) Thickning the suction reed valve, C3 from $0.178 \mathrm{t}$ to $0.203 \mathrm{t}$ (4) Extending tumbling process, C4.

For the second ALT, three samples locked near 17,000 cycles. The root causes of the problematic compressor system were as follows: (1) the erode of the crank shaft and (2) 
the intrusion between crank shaft and thrust washer. The design alternation was provided to the heat treatment on the crank shaft, $\mathrm{C} 5$.

In the third ALT, there were no design issues in the compressor system until the parametric ALT was performed to 49,000 cycles. We thus deduced that the design alterations obtained from the first and second ALTs were sucessful. Table 4 abridges the parametric ALT outcomes. With the altered designs, the last compressor system samples were assured to fulfill the lifetime target - B1 life 10 years.

Table 4. Compressor ALT results.

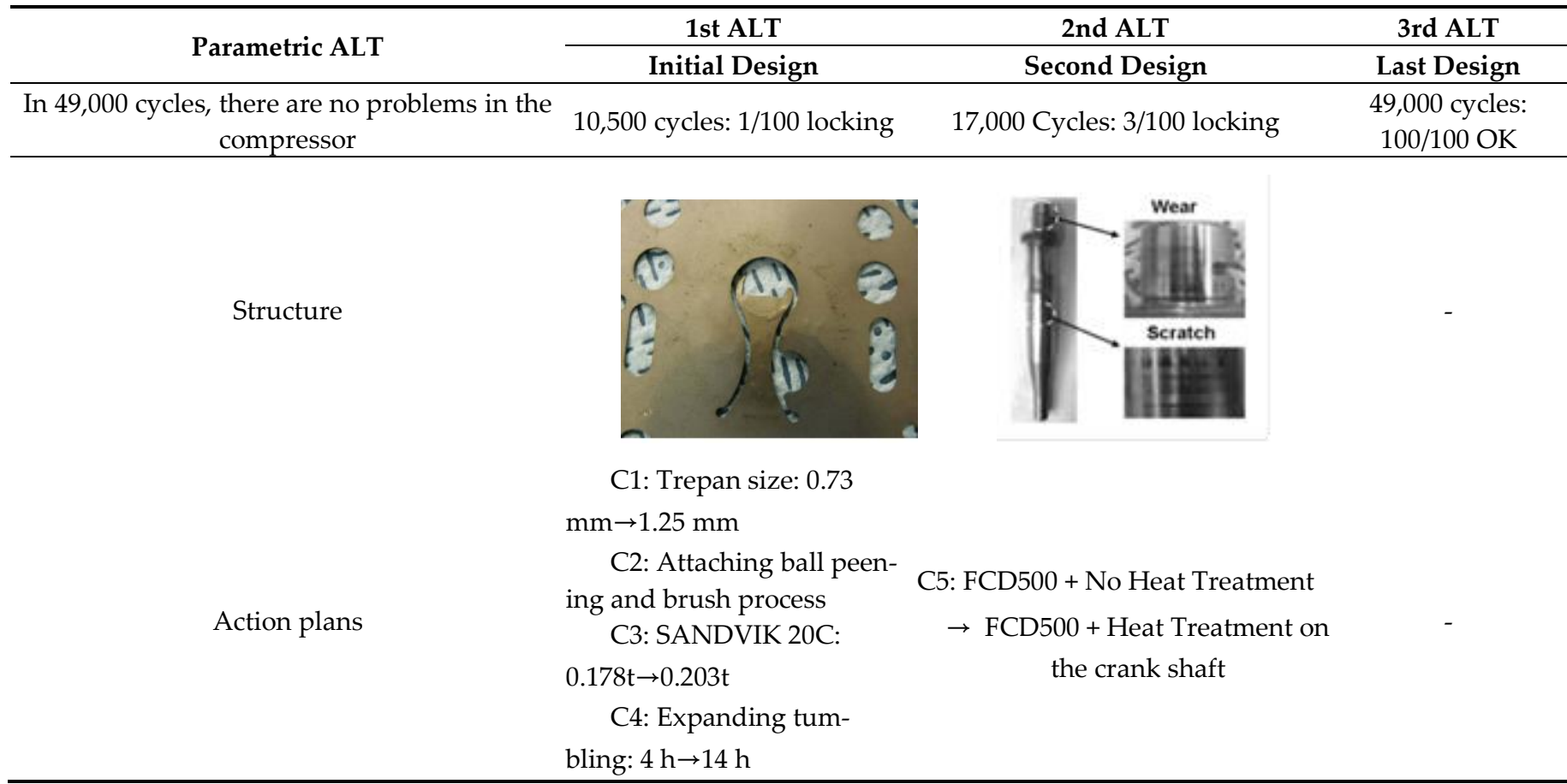

\section{Conclusions}

To enhance the lifetime of the new compressor in a domestic refrigerator, we evolved the following systematic reliability method: (1) the system BX lifetime formed the whole parametric ALT plan, (2) the parametric ALT with design alternatives, and (3) decide if the last product design fulfills the mission cycles. As a test instance, we investigated the design of a returned compressor from the marketplace.

In the market and the first ALT, the fractured suction reed valve in a compressor came from the next design defects: (1) an amount of overlap with the valve plate; (2) a sharp-edged on the valve plate; and (3) insufficient width of the suction reed valve (SANDVIK20 C0.178t). As design alternatives, the trepan on the valve plate was enlarged from $0.73 \mathrm{~mm}$ to $1.25 \mathrm{~mm}$ and a ball peening process was attached to remove its sharp edge.

For the second ALT, three samples locked near 17,000 cycles because of (1) the erosion of the crank shaft and (2) the intrusion between crank shaft and thrust washer. As action plans, we gave the heat treatment on the crank shaft.

Finally, there were no issues during the third ALT. The compressor systems were assured to fulfill the lifetime objective - B1 life 10 years. By examing returned products from the marketplace and performing parametric ALT with design alternatives, the 
evoved systematic reliability method turns out to be successful in enhancing lifetime of compressor system and securing the reliability standard of the last design were fulfilled.

This new systematic reliability method would be relevant to mechanical systems such as refrigerators, airplane, automobiles, and construction equipment. To utilize this, engineers should comprehend why products are unsuccessful in. In other words, if there are design defects in the structure that is subjected to repeated loads, the product will fail in its lifetime. Engineers also is required to recognize the load attributes of a mechanical system so that the parametric ALT can be performed until the needed number of mission cycles under elevated states. Eventually, engineers can utilize parametric ALT to recognize and modify design issues of a mechanical system.

Author Contributions: S.W. conducted the conceptualization, methodology, analysis, and testing and wrote the article. D.O. checked the analysis and writing for original draft. M.M.T and S.M.A review and edit the paper. D.E.W. supervised the research and paper preparation. All authors have read and agreed to the published version of the manuscript.

Funding: This research received no external funding

Institutional Review Board Statement: Not applicable

Informed Consent Statement: Not applicable

Data Availability Statement: The data presented in this study are available on request from the corresponding author.

Conflicts of Interest: The authors state no conflicts of interest.

\section{Abbreviations}

A

$B X$

$E_{a}$

$e$

F

$F(t)$

$h$

$h^{*}$

$J$

K

$\Delta L$

Lв

$N$

$\triangle P$

$P D$

$P_{c}$

$P_{e}$

$P_{\text {suc }}$

$P_{\text {dis }}$
Cross-sectional area of the capillary tube, $\mathrm{cm}^{2}$ time that is an accumulated failure rate of $X \%$, durability index activation energy, $\mathrm{eV}$

effort

flow

impact force, $k N$

unreliability

testing cycles (or cycles)

nondimensional testing cycles, $h^{*}=h / L_{B} \geq 1$

junction equation

Boltzmann's constant, $8.62 \times 10^{-5} \mathrm{eV} / \mathrm{deg}$

Capillary tube length in the two-phase

target BX life and $x=0.01 X$, on the condition that $x \leq 0.2$

number of test samples

Pressure difference between the condenser and evaporator, MPa

Volume flow rate in compressor, $\mathrm{m}^{3} / \mathrm{s}$

Pressure in the condenser, $\mathrm{MPa}$

Pressure in the evaporator, $\mathrm{MPa}$

Pressure at compressor suction, $\mathrm{MPa}$

Pressure at compressor discharge, $\mathrm{MPa}$ 
Q amount of energy absorbed or released during the reaction. For the semiconductor total number of dopants per unit area

$Q_{c} \quad$ Heat transfer by temperature difference in the condenser, $\mathrm{kW}$

$Q_{e} \quad$ Heat transfer by temperature difference in the evaporator, $\mathrm{kW}$

$R \quad$ ratio for minmum stress to maximum stress in stress cycle, $\sigma_{\min } / \sigma_{\max }$

$R \quad$ failed numbers

$R_{c} \quad$ Thermal resistance in the condenser, $\mathrm{K} / \mathrm{kW}$

$R_{e} \quad$ Thermal resistance in the evaporator, $\mathrm{K} / \mathrm{kW}$

S stress

$\mathrm{T} \quad$ torque around the hinge kit system, $\mathrm{kN} \cdot \mathrm{m}$

$\mathrm{T} \quad$ temperature, $\mathrm{K}$

$T_{c} \quad$ Absolute temperature in the Condenser, $\mathrm{K}$

$T_{e} \quad$ Absolute temperature in the Evaporator, $\mathrm{K}$

$t_{i} \quad$ test time for each sample

TF time to failure

X accumulated failure rate, $\%$

$x \quad x=0.01 X$, on condition that $x \leq 0.2$.

$W_{c} \quad$ Compressor power, $\mathrm{kW}$

Greek symbols

$\begin{array}{ll}\xi & \text { electrical field applied } \\ \eta & \text { characteristic life } \\ \lambda & \text { cumulative damage exponent in Palmgren-Miner's rule } \\ \chi^{2} & \text { chi-square distribution } \\ \alpha & \text { confidence level } \\ v_{\text {suc }} & \text { Specific volume of refrigerant at compressor suction, } \mathrm{m}^{3} / \mathrm{kg} \\ \rho & \text { Refrigerant density, } \mathrm{kg} / \mathrm{m}^{3} \\ \eta_{v} & \text { Volumetric efficiency } \\ \omega & \text { Angular velocity, } \mathrm{rad} / \mathrm{s}\end{array}$

Superscripts

$\beta \quad$ shape parameter in Weibull distribution

stress dependence, $n=-\left[\frac{\partial \ln \left(T_{f}\right)}{\partial \ln (S)}\right]_{T}$

Subscripts

0 normal stress conditions

1 accelerated stress conditions

\section{References}

1. Woo, S.; O'Neal, D.; Woldemichael, D.E.; Atnaw, S.M.; Tulu, M.M. Improving the Fatigue of Newly Designed Mechanical System Subjected to Repeated Impact Loading. Metals 2021, 11, 139. 
2. Deming, W.E. Elementary Principles of the Statistical Control Of Quality; Japan JUSE: Hyatt Regency, Tokyo, 1950.

3. Magaziner, I.C.; Patinkin, M. Cold competition: GE wages the refrigerator war. Harv. Bus. Rev. 1989, 89, $114-124$.

4. Taguchi, G. Off-line and on-line quality control systems. In: Proceedings of the international conference on quality control, Tokyo, Japan, 1978.

5. Chowdhury, S.; Taguchi, S. Robust Optimization: World's Best Practices for Developing Winning Vehicles, 1st ed.; John Wiley \& Sons Inc.: Hoboken, NJ, USA, 2016.

6. Allen, P. Design of Experiments for 21st Century Engineers, $1^{\text {st }}$ ed.; Lulu Press: Morrisville, NC, USA, 2020.

7. Duga, J. J.; Fisher, W. H.; Buxaum, R. W.; Rosenfield, A. R.; Buhr, A. R.; Honton, E. J. and McMillan, S. C. The Economic Effects of Fracture in the United States. Final Report, Battelle Laboratories, Available as NBS Special Publication 647-2, Columbus, OH, USA, September 30, 1982,

8. Fatigue. In Elements of Metallurgy and Engineering Alloys; Campbell, F.C.; ASM International: Materials Park, Ohio, USA, 2008.

9. Modarres, M.; Kaminskiy, M.; Krivtsov, V. Reliability Engineering and Risk Analysis: A Practical Guide. $3^{\text {rd }}$ ed.; CRC Press: Boca Raton, FL, USA, 2016.

10. Elsayed, EA. Reliability Engineering. Addison Wesley Longman: Reading, MA, USA, 1996.

11. Hahn, G.J.; Meeker, W.Q. How to Plan an Accelerated Life Test (E-Book). ASQ Quality Press: Milwaukee, WI, USA, 2004.

12. McPherson, J. Accelerated testing. In Electronic Materials Handbook Volume 1: Packaging; ASM International Publishing: Materials Park, OH, USA, 1989; pp. 887-94.

13. McPherson, J. Reliability Physics and Engineering: Time-to-Failure Modeling; Springer: New York, NY, USA, 2010.

14. Griffith, A.A. The phenomena of rupture and flow in solids. Philos. Trans. R Soc. Lond. A 1921, 221, 163-98.

15. Irwin, G. Analysis of stresses and strains near the end of a crack traversing a plate. J. Appl. Mech. 1957, 24, 361-364.

16. Anderson, T.L. Fracture Mechanics -Fundamentals and Applications, 3rd ed.; CRC: Boca Raton, FL, USA, 2017.

17. ASTM E606/E606M. Standard Test Method for Strain-Controlled Fatigue Testing; ASTM International: West Conshohocken, PA, USA, 2019

18. ASTM E399. Standard Test Method for Linear-Elastic Plane-Strain Fracture Toughness of Metallic Materials; ASTM International: West Conshohocken, PA, USA, 2020.

19. ASTM E647. Standard Test Method for Measurement of Fatigue Crack Growth Rates; ASTM International: West Conshohocken, PA, USA, 2015

20. ASTM E739-10. Standard Practice for Statistical Analysis of Linear or Linearized Stress-Life (S-N) and Strain-Life ( $E-N)$ Fatigue Data; ASTM International: West Conshohocken, PA, USA, 2015.

21. Braco, R.; Prates, P.; Costa, J.D.M.; Berto, F. New methodology of fatigue life evaluation for multiaxially loaded notched components based on two uniaxial strain-controlled tests. Int. J. Fatigue 2018, 111, 308-320.

22. Goodno, B.J.; Gere, J.M. Mechanics of Materials, 9th ed.; Thomson Brooks Cole Learning: Boston, MA, USA, 2020.

23. Hertzberg, R.W.; Vinci, R.P.; Hertzberg, J.L. Deformation and Fracture Mechanics of Engineering Materials, 6th ed.; John Wiley and Sons Inc.: Hoboken, NJ, USA, 2020.

24. Reddy, J.N. An Introduction to the Finite Element Method, 4th ed.; McGraw-Hill: New York, NY, USA, 2020.

25. IEEE Standard Glossary of Software Engineering Terminology. IEEE STD 610.12-1990. Standards Coordinating Committee of the Computer Society of IEEE. (reaffirmed September 2002). Available online: https://ieeexplore.ieee.org/document/159342 (accessed on December 31, 1990).

26. Kreyszig, E. Advanced Engineering Mathematics, 10th ed.; John Wiley and Son: Hoboken, NJ, USA, $2011 ;$ p. 683.

27. Grove, A. Physics and Technology of Semiconductor Device, 1st ed.; Wiley International Edition: New York, USA, $1967 ;$ p. 37.

28. Minges, M.L. Electronic materials handbook; ASM International: Cleveland, OH, USA, 1989; Volume 1, p. 888.

29. Karnopp, D.C.; Margolis, D.L.; Rosenberg, R.C. System Dynamics: Modeling, Simulation, and Control of Mechatronic Systems, 6th ed.; John Wiley \& Sons: New York, NY, USA, 2012.

30. Abernethy, R.B. The New Weibull Handbook; Reliability Analysis Center: North Palm Beach, FL, USA, 2000 ; pp. 6-2. 